\title{
Constructive Teaching Design in College English Project-based Learning
}

\author{
Qin Li \\ School of Foreign Languages \\ East China Jiaotong University \\ Nanchang, Jiangxi Province, China \\ E-mail: 22306972@qq.com
}

\begin{abstract}
Students-centered Project-based Learning (PBL) and teacher-authoritative pre-programming pattern are incompatible topics in teaching design, and the combination of them lead to conflicts and puzzled the ambitious developers longing for fundamental changes in College English. To realize the teachers and students' identity transformation, to evolve from the "authority-dependence" relationship into dual subject interacting teaching, the single teaching mode should be replaced by multiple teaching modes and methodologies so as to accomplish the teaching design beyond pre-programming pattern.
\end{abstract}

Keywords- College English; Project-based Learning; Teaching Design; Constructivism.

\section{INTRODUCTION}

Teachers and students both are facing the turning point in the teaching notions from the traditional deeply-rooted objectivism to the newly-rising constructivism. Through the Project-based Learning(PBL) mode, which is being promoted throughout China, a transformation from the Objectivism to Constructivism is happening in China's College English classes. The college English classes are turning away from the pure language knowledge passingon pattern, with the teachers changing from the knowledge source with absolute discourse power to mere cooperator or helper, and the students evolving from the objects supposed to be stimulated, controlled and sustained into active knowledge constructors and spontaneous explorers.

\section{A. Objectivism and Constructivism}

1) Objectivism: In the objectivism teaching notion, the outside world is a rigid, objective and established presence, and the philosophy of objectivism teaching confirms that curriculum should be static and predetermined contents and results in accordance with the settings of academic ranks. The "core" of Objectivism teaching design is Preprogramming. Its main concern is how to execute and complete certain tasks, and with certain formulas, to simplify and interpret a series of complicated procedures, and to execute the plan in different steps in a linear and sequential way [1].

2) Constructivism: Constructivism differs from the traditional Objectivism theories, for Constructivism suggests knowledge exists in consistency with the students' individual experience. Constructivism asserts that knowledge should be constructed by the learners based on their individual exploration into certain fields, and accordingly builds up a personal and unique experience which will in turn lead to the students' independent critical thinking.

\section{B. The Emergence of PBL in College English}

PBL functions as a bridge between using English in class and using English in real life situations outside the class[2]. The emergence of PBL in College English teaching is supposed to break the overwhelming solidified curriculum model, and in this way creates a dynamic, loose College English course with the possibility of integration. If this assumption can be fulfilled, the students will be granted with a brand-new experience to actively construct knowledge rather than simply absorbing it through repeated practice or predefined steps, which demonstrates constructivism.

\section{TEACHING DESIGN IN PBL}

To give the students opportunities to actually construct their own personal experience in learning English, and at the same time their basic language skills could make a leap from the mere receptive-only status into spontaneously creative production, the students should be allowed utmost autonomy in determining the questions, drafting their plans, and finally creating their critical thinking. However, to protect the students' confidence or to achieve the effective control of the curriculum, teachers and teaching materials still design questions for students, and provides them with effective methods which have been proved useful through the predecessors' experiences, so that a perfect results can be predicted and guaranteed.

\section{A. To construct a question}

The Concept of question has two key attributes: first, the question is the gap between the existing state and the target state; second, the revelations or the outcomes of the questions are socially, culturally or intellectually valuable [3]. So, the first critical step in project work is to state the subject, which means to ask a question [4]. A driving question anchored in a real-world problem is the primary feature of PBL [5], and it is supposed to be the Students who explore the resources and ask questions in order to specify their curiosity for the project. Constructivism believes that, in order to enable the learners to complete the construction of the knowledge, namely, to understand the nature, the law and the connections reflected by the knowledge, the best way is to let them go and get soaked into the real world [6]. That is to say, College English teaching should grant the students due respect to their intrinsic motivation. Thus, the students can determine their 
interests or doubts through their own experience, which is an opportunity for them to start a brand new expedition into the unknown but real world.

According to Anchored instruction, real examples or the questions are the foundation (as an "anchor"). And the determination of the real events or real issues is vividly referred to as "anchoring" [7]. Here's a practical example in the teaching design for college English classes based on Unit 7 in the text book, New Experiencing English II, whose pre-programmed objective is Speaking in Public. The traditional teaching design would simply fit the norm and require the students to write a script and give a speech in front of their fellow classmates. However, the opinions collected from the students show that about $10 \%$ of the students are interested in speaking to the audiences sitting in front of them, while the majority others hold a different opinion, which is, these $90 \%$ students either have nothing to share and have no intention to speak to a large audience, or they master not the skills or confidence to make it happen within a short period. In addition, the teacher also ask for advices from the students about the preferable speaking context, and it turns out that the winner is the jobhunting market, which is the authentic and relevant question the students want to research and explore into. So the teacher, with the approval of the students, combines the two questions together, and makes the teaching design into a multi-task project. About $10 \%$ of the students volunteer to prepare and speak in the position of Human Resources for their companies or institutions in front of the whole class, in order to recruit the new blood for posts at different levels with different promised incomes; while the others only need to prepare and speak in a relatively smaller group to persuade the HR to give them their most desirable jobs. In this way, the teaching design fit in the theory of the Scaffold, which means to let the students determine a goal which is closer to their present situation in comparison with the ultimate objectives.

To help the students ask a valuable question, which speaks to the interests of students in a concrete, meaningful way, encouraging students to see the real-world applicability of the concepts they are learning, and allows students to "engage in more idiosyncratic investigations, directing their own learning and making decisions about what they are going to do and how they will do it" [8], teachers must first of all, get to know the students' learning demands, and admit and accept that the students vary in many ways, like motives, linguistic-verbal skills, mathematical-logical skills, and interpersonal-social skills. Accordingly, teachers should create tasks and conditions under which the students personal characteristics, as well as their ambitions and limitations, are recognized and respected. On the other hand, there is still a great chance that the students' questions are ill-structured and the possibility to research and adjust the question still exists. Unable to construct their own method to research, the students may see the impractical nature or the loop holes in their original questions, and they still have a say in either overturning the questions or making some slight adjustments. Therefore, in this phase, teachers should avoid giving the students advices ahead of time, but leave them the window to take their time and pains to actually decide their favorite questions.

\section{B. To solve the problem}

Next, with the teacher's supervision and observation, and the students' understanding of their roles and objectives in the project, students search for the information, select the essence from the vastly abundant storage of data and define the contents of their project. The teacher also provide help to formulate the projects, organize and analyze the data and information, and summarize the findings. The most prevailing investigation measure is searching for information prepared by the predecessors either from the internet or from the library. And the teachers and teaching materials are often so kind and generous to lead the students to some other methods, like the application of interviews, questionnaires, and observations, etc., from which the students can pick their favorite and the most convenient method. It seems to be an effective way to help the students to research into their present question but conceals the truth that the students still conduct their investigation without jumping out of the teacher's frame. And the students will be invariably confronted with a tough situation in the future and they cannot direct their own investigation in an independent manner.

Constructivism and Situated Cognition theory think that the problem is solved with the specific situation, and thus the situation is limited. So, the skills required to solve problems in different situations and areas are also different. According to David H. Jonassen, the problem solving process depends on the students' understanding and characterization of the problem types, including the understanding of the initial state and the target state [9].

To help the students understand the initial state of their problem, the teachers must help the students to figure out the feature of their personal questions. The primary question the teachers should help the students to figure out is to understand if they are handling a Well-structured question or an Ill-structured one.

1) To solve a well-structured problem: A Wellstructured question, also known as transformation question, is the most common kind of question listed in the textbooks right below the texts. To solve these problems needs the learners' full understanding about the conditions and background information, the comprehension of concepts, the utility of rules and principles. This process involves multiple components of the problem, such as a clear initial state, a known target state, and number of restricted logical factors.

This once dominant IDEAL problem-solving pattern can be classified into five steps, identifying the potential question, defining the question's characterization, exploring for practical strategies, implementing the strategies, and reviewing or assessing the outcome. To identify the question means to figure out the target status from the statement of the question, that is to say, to know a satisfying and favorable objective as well as possible measures to achieve it. It should be noted that the problem's features are constructed based on the task by students individually, not merely generated from the context. And then the students need to see through the question and try to see the familiar points echoed to their prior knowledge or experience. The solution to any 
problem is derived from the problem domain in the students' mind, working in association with the previously created domain knowledge, hypothesis generation and problem solving methods discovery, which are all necessary to solve the problem. With the preparation of the first two steps, students are now ready to act, and it is a natural option that they will follow their familiar path to solve their problem. Some students will just brainstorm and come up with some methods to deal with their problem, which is not recommended, for this pattern can only be guaranteed feasible through personal intellectual level, which is totally unreliable. Some students tend to break down their target status, and to determine in the complex target the multiple minor objectives, which are more convenient and possible for the students to handle with their present competence, and then they solve the minor questions one by one, from the critical questions to the less significant ones, until they accomplish their predetermined goal. Other students solve their final problem periodically, which means they start from scratching the surface and then dig in step by step, until they reach the core.

As we mentioned above in the teaching design based on the project of Speaking in Public via Job-hunting, the question concerning the student HRs is basically a Wellstructured question, for the HRs already know all the components of the problem that they need to solve. Their target state is clear, which is to find the right candidate for each position they set up. Some students are already equipped with the ability to solve the problem, but sometimes, many students may still need help from teacher to break the complex down to see the potential but necessary minor tasks, such as preparation for their propaganda and speech, the settings of various posts, the arrangements for the interview, and finally effective assessments to make up the final decisions. It's better that the teacher not to tell them directly the result, but to let them construct their own understanding and experience through learning and taking pains. In the process of their constructing, reasonably, student HRs will determine the companies or institutions they serve according to their own majors, interests, expectations, and emotional preference. Since they've already obtained the relevant knowledge and understanding in their field and some of them even managed to probe into the labor market to get the firsthanded touch. The path to their target state is affirmatively narrowed down and an accurate answer has been universally acknowledged as the standard answer. In this case, the student HRs have a clear task to gather information of the companies or institutions' propagating materials, history and culture, job settings, employee benefits, and related interview arrangement. Most of the student HRs can track down methods to test the candidates, or even find specific questions for interview from the internet or their predecessors' experience. And for assessment, once they get the hands they need, their job is fulfilled.

Actually, the teacher should stay invisible in the students dealing with a well-structured question. If needed, the teacher should not immediately feed the susceptible students with professional opinions, but to bring in the prior cases for the students to research and learn.
2) To solve an Ill-structured problem: Ill-structured question exists in or arises from a particular situation, with no definition, no enough variables, and no limitation or boundary [10].These Ill-structured questions frequently falls into the category of case study, strategy study, and dilemma study, the typical Ill-structured questions. And because of the lack of the knowledge learned within the academic circumstances, these questions can hardly be responded with definite or affirmative solutions.

Instead of being created by the authorities of the educational system, an Ill-structured problem happens naturally in certain situation in the real world. Therefore, the students must look at the situation and determine the nature of the problem. To solve an Ill-structured problem, the students should take the first step to determine whether the problem is the real problem they need to solve to achieve their final objective, for many Ill-structured problems are fake or false, and those questions are presented with the necessary conditions concealed or obscured. For example, a patient complained that he could not sleep well at night, and the doctor examined him thoroughly only to find there was nothing wrong with his physical condition. In that condition, the doctor might as well check the neighborhood of the patient's residence, to see if the patient was disturbed, or turn to the patient's psychological condition to find out the patients hidden sufferings. If it turns out to be the neighborhood that bothers the patient, then any efforts made to choose the right medication would be meaningless. Thus, the real question here is not "how to ensure the patient's tight sleep", but "how to keep the neighborhood in order".

The second step is to identify and clarify a variety of views, grounds and points from the persons of interests. With the real question determined, the students expect no easy job, for unlike a Well-structured question, an Illstructured question is not an issue of convergence, whose strategy or strategies cannot be simply summed up from the prior cases. In fact, the Ill-structured question is essentially dialectical, which requires the students to reconcile various contradictions. One cannot determine which concepts, rules and principles are necessary to form a solution, and how to put them into utilization, because not logical consistency can be found among concepts, rules and principle in particular application.

And the third, an Ill-structured question has many possible solutions, and it is the students' perception towards the limiting condition that leads to their final decision. The process of generating a solution is an innovative process, which not only depends on the previous experience, but also depends on some irrelevant idea and emotion, during which learners are constructing their own models to reason their own problems, which will help them to identify and select or synthesize a certain solution.

So, teachers ought to understand that an Ill-structured question has different solutions in various conditions; and mostly there is no solution that can be universally acknowledged, and it is far beyond the teachers' reach to prepare for a perfect, or to put this in a safe way, a superior answer to each question. Accordingly, in the teaching design, teachers should see themselves as mere observer or coordinator so that the learners can go through the process 
in which an effective interpersonal interaction is involved, the students' personal opinions or notions are stated, and students can see and grasp the chances to create something new.

\section{To conduct the presentation}

During the presentation planning phase, students define the essential points in their project and decide on how to present the project. Nowadays, a manifestation assisted by multimedia technology works as the dominant form of the live presentation. The computer-aided English teaching model can make up for the deficiency of the traditional College English teaching, and be greatly accepted and favored by the students [11]. Actually, the teachers can do better. A labor market, a press conference, a bidding assembly, a recruit on-spot, and even a court can be simulated in the traditional classroom to fulfill the contextualization, in which the students can put their toes into the water and gradually get soaked in the actual real world. According to David Nunan, tasks with a real-world rationale require learners to approximate, in class, the sorts of behaviors required of them in the world beyond the classroom [12].

\section{The Assessment}

To evaluate the students performance in the presentations or reports, the teachers could see the gap between the initial state of the problem and the final state, as well as the remaining distance in between easily as long as the project is Well-structured. But for Ill-structured project, with no affirmative answer to various overlapping questions, teachers should design a full assessing system, in which the students individually or mutually construct their own judgment and introspection into their own work. In this way, the learners are driven to closely monitor process of handling the questions, like how can the objectives be achieved by the proposed method, whether the method fits the limitations and conditions hidden in the questions, whether the solution is globally applicable or just fit in this very case? After testing and assessing the most effective solutions, the learners should learn to apply this solution to other problems, therefore the significance of the solution and the possible corresponding problems can be summarized. Thus, the students problem-solving skills can be integrated and constructed.

\section{CONCLUSION}

Traditional language teaching methodologies give us structure and stability [13] but in the constructive Projectbased Learning, teaching design is a recursive, nonlinear or even chaotic process. Excursiveness means repeatedly adjustment on the same problem such as learning analysis, teaching objectives; nonlinear, means there is nothing dominant enough to be the initial task the students have to begin with. Teaching design can only find the existence of some problems in the specific application situation in order to accurately, and to make a correction or improve the decision making according to the changes of the situation. A recursive evaluation, proper start and re-designed plan shall be formulated by the user or expert [14]. To apply
Constructivism to the PBL, through thorough discussion and negotiation, teachers should help the students choose their own projects and create learning opportunities based upon their individual interests and strengths, and allow the students to apply multiple intelligences in completing a project, which means the teachers should avoid being arbitrary to interfere with the students' intrinsic motivation, and be brave enough to apply flexibility to the teaching design and practice. A wise teacher will not lead the student into his or her own storehouse of wisdom, but the student own thinking threshold [15].

\section{References}

[1] Zhong Zhixian, Innovating the Instructional Model in Higher Education: A perspective of Instructional Design. [M] Beijing, Educational Science, 2008: 57

[2] Zhang Yiying, Project-based Learning in Chinese College English Listening and Speaking Course: From Theory to Practice. Canadian Social Science Vol. 11, No. 9,2015, pp. 40-44: 42

[3] Jonassen D. Toward A Design Theory of Problem Solving [J]. Educational Technology Research and Development, 2000, 48(4): 64)

[4] Zorica Antić and Dragana Spasić: Project-based learning in English for medicine. Acta Medica Medianae 2012, Vol.51(2): 51

[5] Blumenfeld P, Soloway E, Marx R, Krajcik J, Guzdial M, Palincsar A. "Motivating Project-Based Learning: Sustaining the doing, supporting the learning". Educational Psychologist. 1991; 26(3-4): 369-98

[6] Fan Lin, Zhang Qiyun: The Combination of Constructivism and English Language Teaching Reform. Foreign Language and Their Teaching. 2003(4) Serial No 169: 28-32. 29)

[7] Liu Yanju: Anchored Instruction Model and the Diversified Participation of Teacher-The Application of Constructivism in College Listening and Speaking Courses. Journal of $\mathrm{Xi}^{\prime}$ an International Studies University. 2009(6) Vol 17, No 2: 110-113, 111

[8] Yetkiner ZE, Anderoglu H, Capraro RM. Research summary: Project-based learning in middle grades mathematics. Available from:

URL:http://www.nmsa.org/Research/ResearchSummaries/ProjectB asedLearning Math /tabid/1570/Dafault.aspx)

[9] David H. Jonassen Instructional Design Models for Well Structured and Ill - Structured Problem -Solving Learning Outcomes, p34

[10] Instructional Design Models for Well - Structured and Ill Structured Problem-Solving Learning Outcomes, by David $\mathrm{H}$. Jonassen, ET R\& D, Vo 1. 45. No. 1, 1997, pp. 65- 94 ISSN 10421629.

[11] Shi Bo, Empirical Research on Feasibility and Effect of Computeraided College English Teaching Model, 978-1-4244-49941/09/\$25.00 @2009 IEEE

[12] Nunan, D, Designing Tasks for the Communicative Classroom, Cambridge: Cambridge University Press, 1989.1 989: 40

[13] Yan Wang(2014) College English Classroom Teaching Design Based on DDL, 2014 Fourth International Conference on Instrumentation and Measurement, Computer, Communication and Control 978-1-4799-6575-5/14 \$31.00 (C) 2014 IEEE DOI 10.1109/IMCCC.2014.30108

[14] Zhong Zhixian. The Framework of Instructional Design for the Knowledge Age -- to Promote Learners' Development [M]. Beijing, China Social Science Press, 2006:40)

[15] Yanli Liang, On College English Autonomous Learning Based on Internet and Multimedia, 978-1-4244-7874-3/10/\$26.00 @2010 IEEE 